\section{American Museum Meteorite Collections}

Dr. Chester A. Reeds gives in Bull. Amer. Mus. Nat. Hist. (1937) a detailed catalogue of the meteorites contained in this collection, which in 1935 was transferred from the Department of Geology to that of Astronomy, and is now housed in the new planetarium building. The previous catalogue, by Dr. E. O. Hovey in 1896, showed 45 specimens representing twenty-six falls. The collection now contains 3,744 specimens, representing 546 of the 1,073 falls known to the end of the year 1935. The large number of specimens is partly accounted for by 2,129 stones, ranging in weight from 0.2 to 6,650 grams, from the Holbrook, Arizona, shower of 1912. Notable masses are the three Cape York, Greenland, siderites, the largest of which weighs $36 \frac{1}{2}$ tons, that is, short tons of $2,000 \mathrm{lb}$, and is by far the largest meteorite preserved in a museum; and the Willemette, Oregon, siderite of 14.2 metric tons. Much of the general information in the catalogue, even that relating to American meteorites, is reproduced word for word from the late Dr. G. T. Prior's British Museum catalogue.

\section{Mining Industry of Canada}

THE Department of Mines of the Dominion of Canada has issued as usual its report for the Fiscal Year ending March 31, 1936 (Ottawa : King's Printer, 1936. 25 cents). This is a valuable paper and deserves careful study, especially the opening pages signed by Charles Camsell, Deputy Minister of Mines, which give a brief review of the whole mining industry of Canada; of course, the record of the gold industry is exceptionally important owing to the increased price of gold, but the base metals, copper, lead and zinc, also improved and played an important part in the increased value of the exports of base metals. This opening chapter is followed by fuller accounts of the various divisions included under mines, such as mineral resources, ore dressing and metallurgical, fuels and fuel testing, etc.

\section{Centenary of Van der Waals}

IN commemoration of the birth of J. D. v. d. Waals on November 23, 1837, an international conference on interaction between molecules will be organized by the "van der Waals Fonds" and the "Nederlandsche Natuurkundige Vereeniging". The ordinary sessions will be held in the van der Waals Laboratorium at Amsterdam on November 25 and 26, and an official celebration will take place on November 27. The object of the conference is to give a survey of some of the recent work connected with the idea of van der Waals forces. The programme will be published later. Sufficient time will be left for general discussion. A special number of Physica will appear during the conference; it is hoped to be able to publish in this issue a number of papers on a variety of questions having some relation to the work of van der Waals. Physicists willing to contribute to it should send in their manuscripts before October 15, and though it will be impossible to read all these papers * during the conference, it is hoped that they will play an important part in the discussions. The organizing committee, comprising Prof. J. D. v. d. Waals, Dr. A. Michels, Prof. Dr. J. A. Prins and Dr. F. B. G. Casimir, van der Waals Laboratorium, Nieuwe Achtergracht 129, Amsterdam (C), will be glad to give further information.

\section{Solvay Conference}

THE Institut International de Chimie Solvay has issued personal invitations to its sixth chemical conference, which is to take place in Brussels on October 4-9, the chosen subjects for discussion being vitamins and hormones. Eight main papers have been promised, namely : P. Karrer, a general report on vitamins; $H$. von Euler, carotenoid and $B_{2}$ vitamins; Ad. Windaus, vitamins $\mathrm{D}$ and $\mathrm{B}_{2} ; \mathrm{W} . \mathrm{N}$. Haworth, ascorbic acid; A. Szent-Györgyi, physio. logical and therapeutic properties of the vitamins; L. Ruzicka, a general report on hormones; E. Laqueur, sex hormones; T. Kögl, vegetable hormones. Including those named, some twenty-five of the leading workers in these subjects have accepted invitations, so that very valuable discussions should take place during the eight sessions.

\section{Announcements}

THE Harben Lectures for 1937 will be delivered in the Lecture Hall of the Institute of Hygiene, London, on October 11,12 and 13 at 4.30 p.m. by Prof. E. C. Dodds, Courtauld professor of biochemistry in the University of London, on "The Theoretical and Practical Significance of Endocrinology".

The third National Coal Convention will be held at Harrogate on October 6-7, when the speakers will include Lord Horder and Sir Frederick Sykes, chairman of the Miners' Welfare Committee.

Tre Lilienthal Society of Aviation, founded in 1936, will hold its annual congress at Munich on October 12-14, when there will be an exhibition relating to aviation. Further information can be obtained from the general secretary of the Society, Wilhelmstrasse 148, Berlin, S.W.68.

THE ninth International Congress on Psychotherapy will be held in Copenhagen on October 2-4. Prof. C. G. Jung of Zurich and Dr. Paul Bjerre will give the inaugural addresses. The chief subjects for discussion will be psychotherapy in general practice and "Can Psychotherapy be Taught ?" Further information can be obtained from the general secretary, Dr. Olaf Brüel, 2 Amagertorf, Copenhagen K.

A sessional meeting of the Royal Sanitary Institute will be held on October 1 in the Town Hall, Llandudno, when Dr. D. A. Powell, principal medical officer of the King Edward VII Welsh National Memorial Association, will open a discussion on "Tuberculosis in Wales-a Stock-taking", and Dr. R. W. Dodgson, director of the Ministry of Agriculture and Fisheries Shellfish Services, will speak on the Conway mussel purification tanks. On October 2 a visit will be paid to the Conway Station for a demonstration and inspection of the tanks. Further information can be obtained from the Secretary, Royal Sanitary Institute, 90 Buckingham Palace Road, S.W.l. 